\title{
A Descriptive Study on Prevalence of Occupational Health Hazards among Employees of Selected Sugarcane Factory in Deharadun, Uttarakhand
}

\author{
Rahul Bisht, Monika Rawat, Naresh Singh, Neha Bisht, Pooja Rawat, Pooja \\ Thapliyal, Priyanka, Priyanka Chamoli, Ranjana Pal, Vinita Kandwal* \\ Mrs. Laxmi Kumar**, Mr. Jayant Abhishek Gideon*** \\ $* 4^{\text {th }}$ year B.Sc. Nursing Students, Himalayan College of Nursing, HIHT, Dehradun \\ **Lecturer, Obstetrics \& Gynaecological Nursing, Himalayan College of Nursing, HIHT, Dehradun \\ ***Nursing Tutor, Himalayan College of Nursing, HIHT, Dehradun.
}

\begin{abstract}
Occupational health hazards have deleterious effect on the individual health and safety as well as the organizational effectiveness. Emerging occupational health problems are to be tackled along with existing public health problems like communicable disease, malnutrition and inadequate medical care. Globalization and rapid industrial growth in the past few years have added further to complexities of occupational health related issues. Quantitative approach was used and research design was descriptive survey research design. Sample were factory employees of sugarcane factory, sample size was 100 and sample technique was convenient sampling, setting for the study was sugarcane factory of Doiwala, Dehradun, and tool used were checklist related to occupational health hazards. Majority (36\%) of the subjects were between 47 to 56 years, majority (39\%) subjects had educational status up to primary, majority (57\%) of the subjects having monthly income more than 15000, majority (55\%) of the subjects were from nuclear family, majority (55\%) of the subjects were non vegetarian, majority (77\%) of subjects were living in rural areas, majority (33\%) of subjects were consuming tobacco, majority (81\%) of subjects were having working experience more than 10 years, majority (95\%) of the subjects were having working hours more than 8 . Through this checklist we found that (42\%) of subjects were having back ache, joint or muscles problems, (52\%) of subjects were suffering from vision problems and (81\%) of a subject says that PPE is not available for all workers.
\end{abstract}

Keywords: Prevalence, Occupational Health Hazards, Employees, Factory

\section{Introduction}

India is a vast country with a surface area of about 3.3 million square kms. The total population of India according to 2014 census was 1.27 billion. About $72 \%$ of its population lives in the rural area. Emerging occupational health problems are to be tackled along with the existing public health problems like communicable diseases, malnutrition, poor environmental sanitation, and inadequate medical care. Globalization and rapid industrial growth (about $8 \%$ annual economic growth) in the past few years have added further to complexities of occupational health related issues ${ }^{1}$. Occupational health hazards have a deleterious effect on the individual's health and safety as well as organizational effectiveness. The term occupational safety describes a comprehensive concept for the protection of employees from health risks in the workplace, which results from the job related acturity itself and from biological, chemical and physical effects ${ }^{1}$.

\section{Need of Study}

Repeated and long term exposure to bagasse dust in sugar cane industries can lead to an array of severe respiratory problems like bagassosis and chronic respiratory that may have lasting effects, even after exposure ceases. Certain sugar cane industries, because of the nature of their location, work and environment are more at risk for occupation disease like bagassosis than any other diseases. In India, the studies revealed that in 2010, $40-59 \%$ of workers in different occupational work environments suffered from one or more respiratory ailments. As much as $36-40 \%$ of the workers reported work-related symptoms which are close to similar data from western countries ${ }^{2}$.

Sugar cane worker have an increased risk of lung cancer; this may be related to the practice of burning foliage at the time of cane-cutting. Bagassosis is also a problem specific to the industry as it may follow exposure to bagasse (a by-product of sugar cane). The workers may also be affected by chronic infections which reduce their productivity. The legal framework for their protection is often inadequate. In conclusion, areas of future research are suggested ${ }^{3}$.

Back problems were the second most mentioned risk, related to long periods in a seated position. Other risks reported included breathing problems related to dust, physical injuries due to positioning and 
repetitive movements in operating the harvesters and the risk of fire due to machines overheating. Concerning the occurrence of occupational accidents, $33.3 \%$ of the cutters stated they had already had several machete accidents while cutting sugar cane, which caused cuts on the upper and lower limbs, mainly on the hands, legs and feet. During the interviews, workers acknowledged that use of PPE could minimize the risk of accidents. According to the literature, the most frequent occupational accidents for manual cutters are caused by machete handling and bites of venomous animal, while accidents for mechanical cutters occurred from collisions and falls during machine maintenance. Another set of health problems for sugar cane workers are respiratory diseases due to constant exposure to soil dust and soot from the burned sugar cane ${ }^{4}$.

\section{Statement of Problem:-}

A descriptive study on prevalence of occupational health hazards among employees of selected sugarcane factory in Dehradun, Uttarakhand.

Objectives:- To assess the prevalence of occupational health hazards among employees of selected sugarcane factory.

Assumptions:-The researchers assumed that-

1. The sugarcane factory employees will provide true response.

2. The sugarcane factory employees will have some short of occupational health hazards.

\section{Delimitation:-}

1. The study was delimited to only the factory employees of sugarcane factory, Doiwala.

2. The study was delimited to factory employees who were willing to participate in the study.

3. The study was delimited to factory employees who are present at the time of data collection.

\section{Methodology}

The research design used in this study was descriptive survey research design. The study was conducted at sugarcane factory of Doiwala ,Dehradun, Uttarakhand . The sample size was 100 sugarcane factory workers, selected by convenient sampling technique. The tool used for the data collection was checklist related to prevalence of occupational health hazards consisting of section 1 (demographic baseline data such as age, educational status, monthly income, type of family, years of experience, dietary habits, area of residence, substance abuse and working hours) and section 2 (consisting of 48 questions related occupational health hazards in nine aspects i.e. health history, CNS problems, respiratory problems, cardiac problems, musculoskeletal problems, skin problems, eye, ear and nose problems, environmental exposure and miscellaneous).Data was collected by interview method

\section{Results and Findings}

Sociodemographic Profile of study participants- 36\% of employees were in the age group of $47-56$ years. Majority (39\%) of the employees were having primary education .Majority (57\%) of the employees were having monthly income more than Rs. 15000/. Majority (55\%) of employees were from nuclear family. Majority (55\%) of the employees were non-vegetarian .Regarding the area of living most of the employees (77\%) belonged to rural area. Majority (33\%) of employees were having habit of consuming tobacco. Majority ( $81 \%$ ) of employees were having working experience more than 10 years. Majority $(95 \%)$ of the employees working duration were 8 hours.

Prevalence of occupational health hazards among Sugarcane factory employees- Distribution of employees according to musculoskeletal problems- $42 \%$ of employees were having back, joint or muscle problems, $24 \%$ of employees were taking pain medication, $22 \%$ of employees were suffering from hand arm vibration and $19 \%$ of employees were suffering from neck problems.

Distribution of employees according to eye, ear and nose problems-52\%of employees were suffering from vision problems, $29 \%$ of employees had burning in eyes, stinging or tearing eyes, (98\%) of employees didn't ever had bleeding from their nose and $15 \%$ of employees had hearing problems.

Distribution of employees according to cardiac problems-20\% of employees were suffering from hypertension, $15 \%$ of employees were suffering from chest pain, $98 \%$ of employees didn't ever got heart attack and $18 \%$ of employees were taking blood pressure medication.

Distribution of employees according to skin problems- $16 \%$ of employees were suffering from skin problems like eczema, $8 \%$ of employees were suffering from skin infection, $22 \%$ of employees were have numbness or 
tingling sensation in arms and hands, $7 \%$ of employees were have serious cuts in their hands or feet $28 \%$ of employees says that they didn't wash their hands with soap and water and $94 \%$ of employees says that they wash their hands before and after eating food.

Distribution of employees according to respiratory system problems- Only $1 \%$ of employee was suffering from bronchitis, $6 \%$ of employees were suffering from cough with sputum, $4 \%$ of employees were suffering from asthma, $15 \%$ of employees suffering from cough with chest pain, $12 \%$ of employees were suffering difficulty in breathing. $12 \%$ of employees says that they have being out of breathe when making physical efforts and $8 \%$ of employees had being up phlegm from chest.

Table 1: Sociodemographic Profile of study participants $\mathrm{N}=100$

\begin{tabular}{|c|c|c|c|}
\hline S.No & Socio demographic profile & Frequency & Percentage \\
\hline \begin{tabular}{l|}
1 \\
1.1 \\
1.2 \\
1.3 \\
1.4 \\
1.5
\end{tabular} & $\begin{array}{l}\text { Age in years } \\
\bullet \quad 17-26 \text { year } \\
27-36 \text { years } \\
37-46 \text { years } \\
47-56 \text { years } \\
57-66 \text { years } \\
\end{array}$ & $\begin{array}{l}7 \\
8 \\
35 \\
36 \\
14 \\
\end{array}$ & $\begin{array}{l}7 \% \\
8 \% \\
35 \% \\
36 \% \\
14 \% \\
\end{array}$ \\
\hline $\begin{array}{l}2 \\
2.1 \\
2.2 \\
2.3 \\
2.4\end{array}$ & $\begin{array}{l}\text { Educational status } \\
\text { Primary } \\
\text { Secondary } \\
\text { Higher secondary } \\
\text { Graduate and above }\end{array}$ & $\begin{array}{l}39 \\
35 \\
21 \\
5\end{array}$ & $\begin{array}{l}39 \% \\
35 \% \\
21 \% \\
5 \%\end{array}$ \\
\hline \begin{tabular}{l|}
3 \\
3.1 \\
3.2 \\
3.3 \\
3.4
\end{tabular} & $\begin{array}{l}\text { Monthly income } \\
\text { Less than } 5000 \\
5001-10000 \\
10001-15000 \\
\text { More than } 15000\end{array}$ & $\begin{array}{l}3 \\
14 \\
26 \\
57\end{array}$ & $\begin{array}{l}3 \% \\
14 \% \\
26 \% \\
57 \%\end{array}$ \\
\hline \begin{tabular}{l|}
4 \\
4.1 \\
4.2 \\
\end{tabular} & $\begin{array}{l}\text { Types of family } \\
\text { Joint family } \\
\text { Nuclear family }\end{array}$ & $\begin{array}{l}45 \\
55 \\
\end{array}$ & $\begin{array}{l}45 \% \\
55 \% \\
\end{array}$ \\
\hline \begin{tabular}{l|}
5 \\
5.1 \\
5.2 \\
\end{tabular} & $\begin{array}{l}\text { Dietary habits } \\
\text { Vegetarian } \\
\text { Non-vegetarian }\end{array}$ & $\begin{array}{l}45 \\
55 \\
\end{array}$ & $\begin{array}{l}45 \% \\
55 \% \\
\end{array}$ \\
\hline \begin{tabular}{l|}
6 \\
6.1 \\
6.2 \\
\end{tabular} & $\begin{array}{l}\text { Area of residence } \\
\text { Urban } \\
\text { Rural }\end{array}$ & $\begin{array}{l}23 \\
77 \\
\end{array}$ & $\begin{array}{l}23 \% \\
77 \% \\
\end{array}$ \\
\hline \begin{tabular}{l|}
7 \\
7.1 \\
7.2 \\
7.3 \\
7.4 \\
\end{tabular} & $\begin{array}{l}\text { Substance abuse } \\
\text { Alcohol } \\
\text { Smoking } \\
\text { Tobacco } \\
\text { Others } \\
\end{array}$ & $\begin{array}{l}28 \\
25 \\
33 \\
14 \\
\end{array}$ & $\begin{array}{l}28 \% \\
25 \% \\
33 \% \\
14 \% \\
\end{array}$ \\
\hline \begin{tabular}{l|}
8 \\
8.1 \\
8.2 \\
8.3 \\
8.4 \\
\end{tabular} & $\begin{array}{l}\text { Working experience } \\
\text { Less than } 2 \text { years } \\
3-5 \text { years } \\
6 \text { - } 10 \text { years } \\
\text { More than } 10 \text { years }\end{array}$ & $\begin{array}{l}6 \\
5 \\
8 \\
81 \\
\end{array}$ & $\begin{array}{l}6 \% \\
5 \% \\
8 \% \\
81 \% \\
\end{array}$ \\
\hline $\begin{array}{l}9 \\
9.1 \\
9.2\end{array}$ & $\begin{array}{l}\text { Working hours } \\
8 \text { hours } \\
12 \text { hours }\end{array}$ & $\begin{array}{l}95 \\
5\end{array}$ & $\begin{array}{l}95 \% \\
5 \%\end{array}$ \\
\hline
\end{tabular}

Figure 1:- Percentage distribution of employees according to musculoskeletal problems.

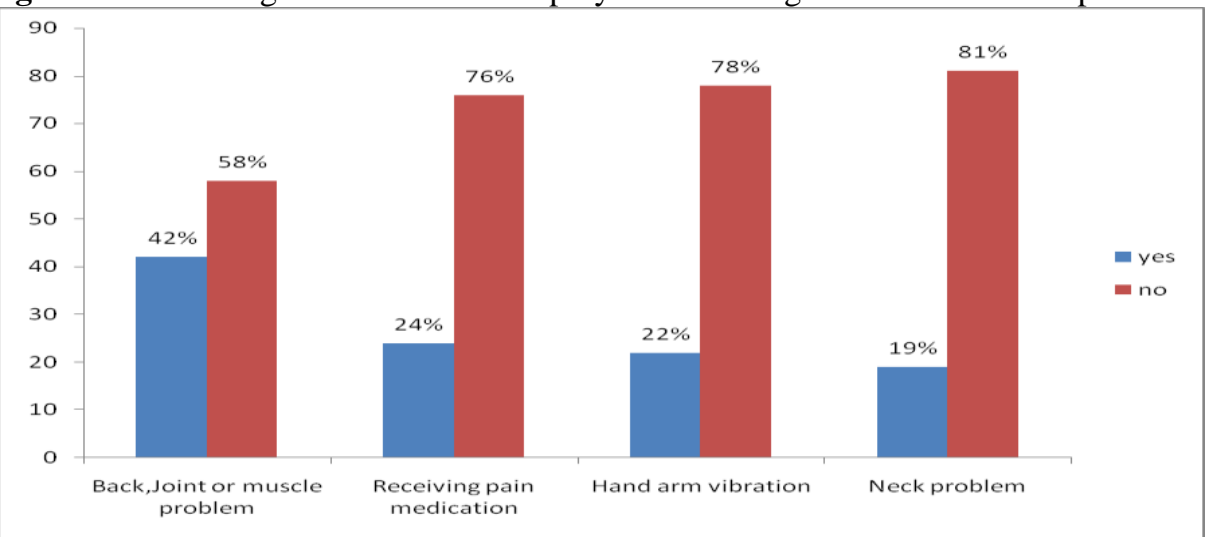


Figure 2:- Percentage distribution of employees according to eye, ear and nose problems.

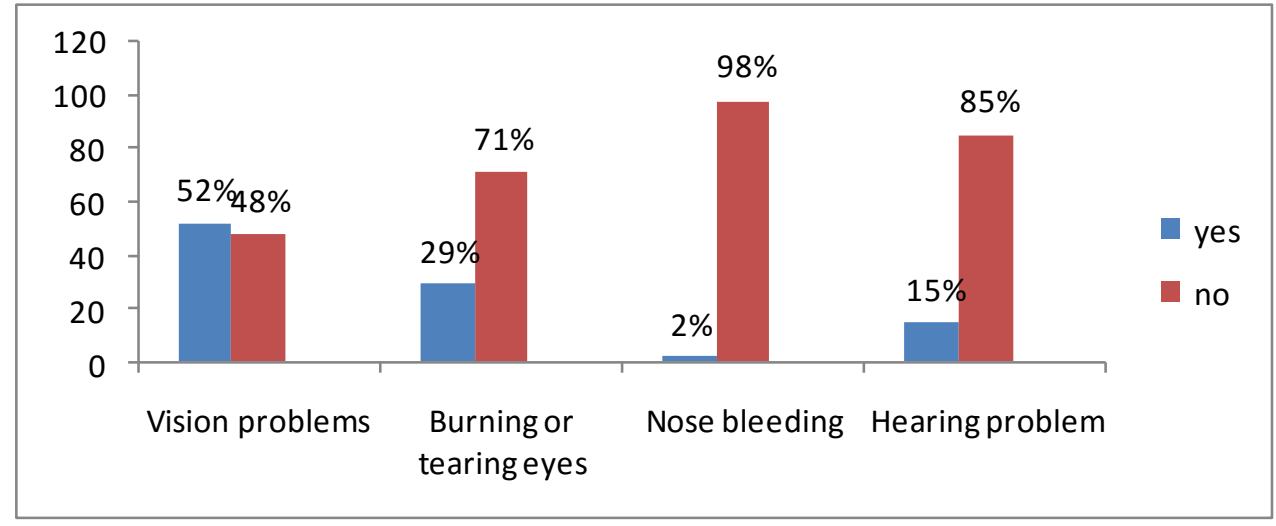

Figure 3:- Percentage distribution of employees according to cardiac problems.

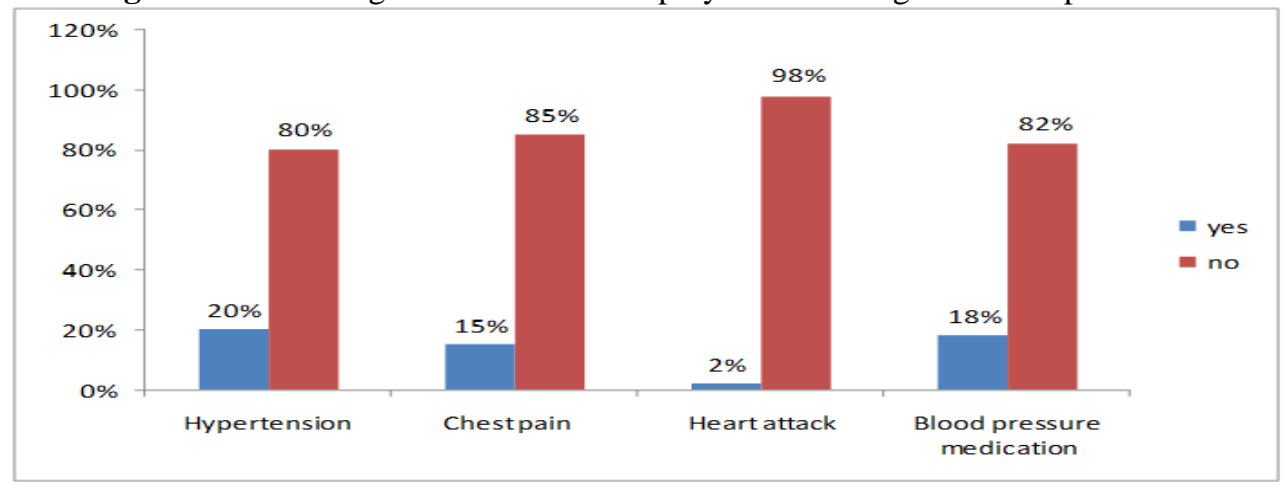

Figure 4:- Percentage distribution of employees according to skin problems.

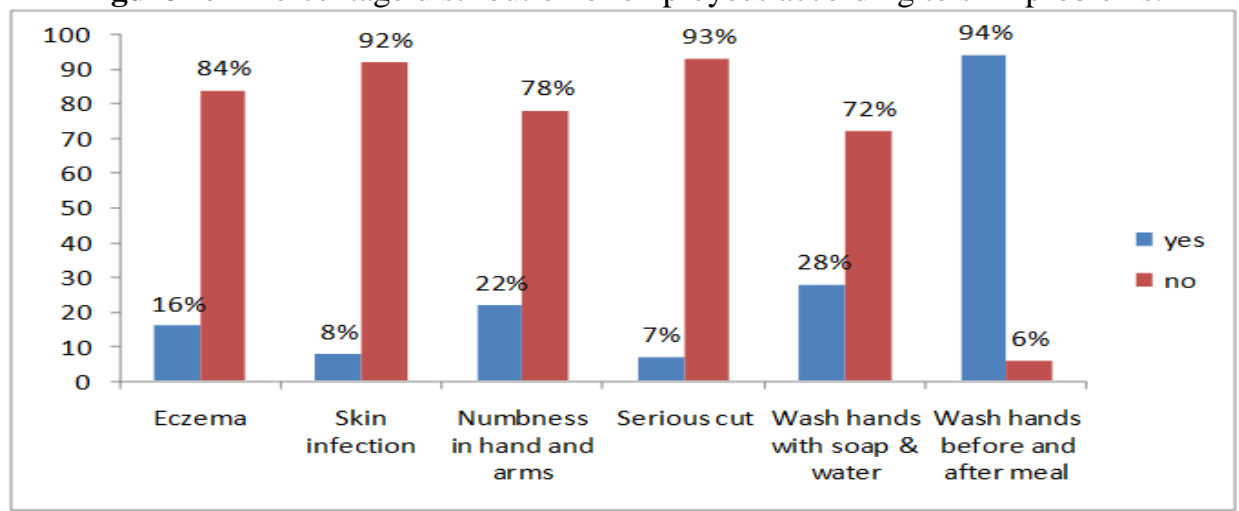

Figure 5:- Percentage distribution of employees according to respiratory system problems

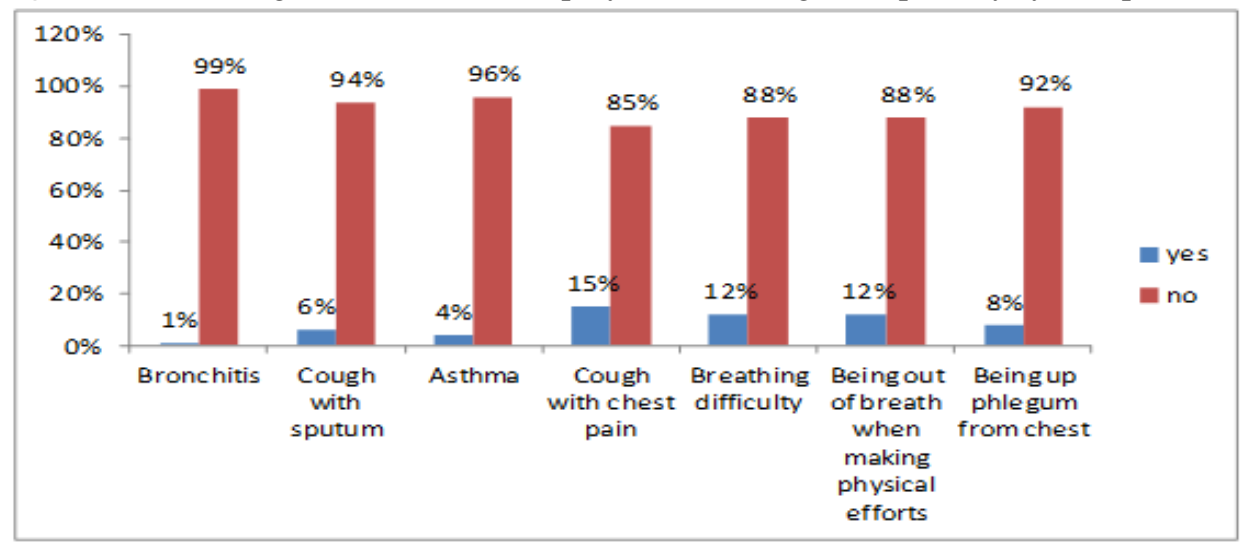




\section{Nursing Implications}

Nursing services:- There is need that occupational health nurse can take active part in educating industrial workers regarding occupational related health hazards.

1. Occupational health nurse can help the industrial workers by providing education regarding occupational hazards and their preventive methods, so that industrial workers can be prevented from it.

2. Occupational health nurse can educate the workers through exhibition and role play.

Nursing administration:- Nursing has become a complex and highly varied descriptive with the rapid growing well developed and well documented scientific and humanistic knowledge base.

1. Nursing administration should provide necessary facilities to nursing staff and encourage use of cost effective audio visual aids and material, models in client teaching.

2. Continue nursing education can be organized by nursing personal to educate them regarding occupational hazards so that nurses can educate industrial workers.

Nursing Education:- Nursing students should be educated about the occupational health hazards and their preventive methods, so that they can educate industrial workers regarding occupational related hazards.

Nursing Research:- There is the need to conduct further research studies in the field related to prevalence of occupational health hazards, planned teaching programme can be given to factory employees related to occupational hazards and comparative study can be done between two factories related to occupational health hazards.

\section{Conclusion}

The following conclusions were drawn on the basis of the present study

1. The findings showed that out of 100 employees $42 \%$ of employees had back, joint and muscle problem and $52 \%$ of employees had vision problems.

2. During the data collection employees also complain that personal protective equipment (PPE) is not available for them.

\section{Acknowledgement}

We give our sincere thanks to Mrs. Sanchita Pugazhendi (Principal and HOD, Community Department), Himalayan College of Nursing for her guidance and supervision provided to us in conducting the present research study. We give our heart full thanks to Mrs. Kamli Prakash (Vice Principal) for her constant support and encouragement.

\section{References}

[1]. Leigh J, Macoskill P,kuosma E,Mandryk.J:Global burden of disease and injuries due to occupational factors.Epidemiology 1999;10 -626 -31[cited on 2014 Feb 13] Available from: www.amrc.org.hk/occupational 20 status.report.India.pdf

[2]. Sahu S, Chauhan L S : A study related to occupational workers( sugar cane industries):2003: [cited on 2014 Feb 14] Available from: www.who.com

[3]. Devendra K. Amree, Claire Infant- Rivard Andre; Prakash.m Durgawale,Pierre Ernst; Occupational Environment 1999: page no 548-552[cited on 2014 Feb 15] Available from: http://www.ilo.org

[4]. Alessi NP, Navarro VL .Saude e trabalho, rural o caso dostra balhadores da cultura canavieira na vegia ode Ribirao Preto, Sao Paulo ,Brasil . Cad Saude Pablica 1997 ;13 Sup 12:111-21[cited on 2014 Feb 16] Available from :www.scielo.br/scielo.php\%3Fscript\% 